\title{
Understanding youth with substance use disorders (SUDs) in Rwanda: A health promotion perspective
}

\author{
James Ngamije ${ }^{1}$, Callixte Yadufashije ${ }^{2}$ \\ ${ }^{1}$ Lecturer, Department of Hospitality, University of Tourism, Technology and Business Studies, ${ }^{2}$ Senior Lecturer, \\ Department of Biomedical Laboratory Sciences and Director of Research and Consultancy at INES Ruhengeri-Institute \\ of Applied Sciences
}

Youth drug abuse has been subject of public concern for many years. In Rwanda, despite nearly two decades of developing prevention initiatives, the problem persists with significant disparities present across the country. This review evaluates a health promotion perspective that addresses the specific needs of vulnerable youth.

Keywords: Youth; Substance Use Disorders; Health promotion

\section{Access this article online}

Website:

http://nepjol.info/index.php/AJMS DOI: 10.3126/ajms.v11i4.28123

E-ISSN: 2091-0576 P-ISSN: 2467-9100

Copyright (c) 2020 Asian Journal of Medical Sciences

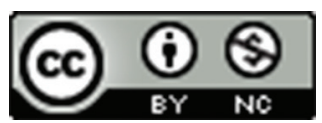

This work is licensed under a Creative Commons Attribution-NonCommercial 4.0 International License.

\section{INTRODUCTION}

Alcohol and drug abuse among the youth are public health concern and family challenges in Rwanda. ${ }^{1}$ According to recent study conducted by the ministry of youth in collaboration with the university of Rwanda, demonstrated that more than half (52.4\%) of the participants reported that they had used one or more substances at least once in their life time and concluded that tobacco, alcohol, marijuana and other substance use are realities in the daily lives of youth in Rwanda. ${ }^{2}$ Drug is any substance in the form of food, drink, capsule, smoke, injection, or smell which is taken through mouth, nose, or skin, and affects the biochemical system of the body, especially the cerebrospinal nervous system. ${ }^{3}$ Motivation of using drugs among the youth varies and depends on individuals. Some of them use drugs to feel good, to feel better, to do better and others just to explore. ${ }^{4}$ Also abuse, addiction and drug-related crime are major and still arising phenomenon in Rwanda, ${ }^{5}$ which might be due to the fact that illicit drugs such as cannabis and local liquors are accessed from neighboring countries. The aforementioned issues underline the importance of health promotion.

\section{NEED FOR HEALTH PROMOTION}

There are five main reasons for a particular health promotion focus on young people. 


\section{PATTERNS OF INITIATION, CONTINUED USE INTO ADULT}

Adolescence is a high-risk period for development of both depressive and substance use disorders. These two disorders frequently co-occur in adolescents and are associated with significant morbidity and mortality. ${ }^{6,7}$ Rwandan adolescents are at heightened risk for the development of both depressive and substance-related disorder as they experience a range of potentially traumatic and other adverse events that increase their risk for alcohol and substance use problem. ${ }^{7}$ Studies focusing on the developmental onset of substance-use have shown that alcohol and drug use before the age of 14 years is associated with a plethora of short- and long-term negative consequences. ${ }^{8}$ In addition, in this cohort, the period of major risk for initiation to cigarettes, alcohol, and marijuana, is completed for the most part by age 20 , and to illicit drugs other than cocaine by age 21 . Those who have not experimented with any of these substances by that age are unlikely to do so thereafter. ${ }^{9}$

Prevalence of regular smoking rises from 1\% at age 11 years to $24 \%$ at 15 years, and over $90 \%$ of adult smokers began smoking as teenagers; similarly, few people start experimenting with alcohol and drugs after their teenage years. ${ }^{10}$ Early-maturing adolescents have been shown to initiate smoking and drinking earlier and to be more likely to experiment with other illegal substances than later-maturing adolescents. ${ }^{8}$ The evidence challenges earlier notions that adolescents moving into adulthood "grow out of" health risk behaviors and mental health problems. ${ }^{10}$

\section{IMMEDIATE EFFECTS OF ADOLESCENT HEALTH BEHAVIORS}

Drug abuse among the youth have a direct effect on immediate as well as long term health outcomes and quality of life to include health (e.g brain dysfunction, NCDs such as cancers) and non-health consequences (e.g unemployment family dysfunction). ${ }^{3,11,12}$ Current major health outcome of youth using drugs is brain and cognitive dysfunction. ${ }^{11-13}$ Using data from the longitudinal Brain and Alcohol Research in College Students (BARCS) study, Meda et al, found that young adults who engage in heavy drinking display greater volume loss in regions such as the frontal cortex and hippocampus. ${ }^{14}$ In addition, greater gray matter decline in heavy users occurred largely in regions responsible for emotion, memory, mental flexibility, and decision making, all of which might have a direct impact on student college success. ${ }^{12}$ With regard to alcohol use disorders and effect of family, studies showed reduction of GMV in this medial temporal region for both individuals with alcohol dependence and those with family history of alcohol dependence ${ }^{15}$ with impact on cognitive functions particularly attention, working memory, and Visio spatial performance in adolescents after initiating alcohol us. ${ }^{11}$ This may be due to increased activation to drug cues in medial frontal/ACC that underlie attention and motivation. ${ }^{16,17}$

Other studies suggested that heavy alcohol intoxication affect function of neurons particularly alcohol might trigger microglia activation, oxidative stress, and pro-inflammatory changes which in turn leads to neurotoxic degeneration and/or prevents genesis of neurons and glia and gray and white matter changes was observed. ${ }^{18,19}$ Cannabis often used by youth can lead to long-term cognitive deficits particularly attention and memory. ${ }^{20}$ Some clinical work has linked adolescent THC use to reduced IQ, increased risk for psychosis, and impaired working memory. ${ }^{21,22}$ However, other scholars showed that exposure to marijuana causes long-term deficit in executive function..$^{20}$

\section{WORRYING COST AND TRENDS IN SUBSTANCE USE DISORDERS (SUDS)}

The 1994 genocide against Tutsi, have placed a great strain on both survivors and former prisoners accused for participation in the Rwandan genocide and their families. Research on effect of genocide on trauma, mental health and psychosocial conditions demonstrated high rates of mental health and psychosocial problems due to the inconceivable, dehumanized brutality that the majority of them had been exposed or witness to. ${ }^{23}$ Family factors that are considered as protective factors, entire family systems as well as the general social fabric that formerly provided support were destroyed due to losses of family members and growing mistrust and fear following the genocide. ${ }^{23}$ Thus, Young people in Rwanda are the most at risk of drug abuse not only because as they are in a period of life when patterns of behavior are being formed but also mental health associated with lack of parents and are most likely to be influenced by family and peers who may be involved in the use of drugs.

According to Aimé Bosenibamwe, Director General of Rwanda National Rehabilitation Services (NRS) noted that beside the amount spend on activities related to prevention, rehabilitation and reintegration, the government is spending Rwf 80 million on rehabilitation per month at Iwawa Rehabilitations Center while Rwf 70 million is spent on Gitagata Rehabilitation Center, besides money spent in districts' rehabilitation centers and money spent on medical care and feeding as a big number of these drug abuser are infected with sexually transmitted diseases to include HIV/AIDS and also suffer Tuberculosis. ${ }^{24}$

Most Rwandan families are already painfully aware and affected by the cost of substance misuse problems. The aim of this study is not to show that drug abuse and addiction 
cause immensely expensive and socially devastating harms and costs that should be used in our development. Rather, the major message from this study is that science now provides a public health oriented approach to translate the available science into effective, practical, and sustainable policies and practices to prevent onset substance use, identify and intervene early with emerging cases of substance abuse and effectively treaty serious substance use disorders. ${ }^{25}$

\section{DEVELOPMENTAL ISSUES}

Adolescence has three important stages including early adolescence, mid-adolescence, and late adolescence. During each period, an adolescent develops psychologically, socially and implicate for health promotion (Table1). The transition from childhood to adolescence is characterized by important biological, cognitive, emotional and social changes with distinct needs in terms of delivery of health promotion messages. ${ }^{8}$ This period is heavily marked by the onset of and progression through puberty, greater autonomy and less self-regulation, and changes in parental and peer relationships. In early adolescence, concrete thinking predominates, with young people generally able to understand only linear "concrete" relations between cause and effect. In this very literal context, messages that smoking causes lung cancer can be rejected as irrelevant; as they know that their parents who smoke for long time do not have lung cancer. ${ }^{10}$

Health promotion messages should begin in early adolescence, as studies focusing on the developmental onset of substance-use have shown that alcohol and drug use before the age of 14 years is associated with a plethora of short- and long-term negative consequences. ${ }^{8}$

\section{CLUSTERING OF HEALTH RISK}

Health risk behaviors cluster in adolescence, meaning that those who are involved in drugs are also more likely to engage in risk sexual behavior, teen pregnancy, academic failure and school dropout, higher risk for assault, suicide, alcohol poisoning, behavioral and mental-health problems, with all alcohol-use and its consequences accounting for almost $4 \%$ of the global burden of health. ${ }^{26}$

\section{SETTINGS FOR HEALTH PROMOTION}

When adolescents become socially disconnected from family, school, community they may seek comfort and a sense of security through drug use, and find support and ready acceptance from other peer's users of drugs. In Rwanda, government need to emphasize on structural issues that exacerbate this problem, such as poor housing, low income, unemployment, poor education and domestic violence. In addition, they are other youth who are at great risk of becoming excluded and marginalized due to their behaviors. Promoting health to community as a whole (for example, policy on zero tolerance on underage drinking) is more effective than simply urging adolescents to behave healthy. O'Donnell suggested five domains of health promotion: (i) Physical (Fitness, nutrition, medical self-care, control of substance misuse), (ii) motional (Care for emotional crisis, stress management), (iii) social (communities, families, friends), (iv) intellectual (Education, achievement, career development and (v) spiritual (Love, hope, charity). ${ }^{27}$ Toumbourou et al, reviewed 178 research articles and suggested that effective health promotion strategies include health promotion schools, social marketing, peer intervention, parent support, and community strengthening, ${ }^{28}$ Using these approaches to address youth with substance abuse in Rwanda and associated harms is of paramount importance. ${ }^{29}$

Strategies include health promoting schools, this includes school based drug prevention. the strategy contains different methods including focusing on well-being and cultures that promote resilience, enabling sustained life skills development, integration of broader curriculum, De-emphasizing of the use of outside presenters, and Development of school-based health and welfare support services. ${ }^{29}$ The second strategy is social marketing. It is based on building careful research and focus group testing, targeting specific age groups and drug use patterns, closely integrating with other prevention elements, providing non-media information through community involvement, setting clear and realistic goals for broad and

\section{Table 1: Implications of adolescent development for health promotion in adolescence}

\begin{tabular}{llll}
\hline & Psychological development & Social development & Implications for health promotion \\
\hline Early adolescence & $\begin{array}{l}\text { Concrete thinking but grasp of } \\
\text { moral concepts; assessment } \\
\text { and adjustment of body image }\end{array}$ & $\begin{array}{l}\text { Realising difference from } \\
\text { parents; start of strong peer } \\
\text { group; start of health risk } \\
\text { behaviors }\end{array}$ & $\begin{array}{l}\text { Start health promotion messages, using } \\
\text { concrete motivators; focus on "here and now"; } \\
\text { use peer educators or role models; current } \\
\text { physical health can be important motivator }\end{array}$ \\
$\begin{array}{llll}\text { Abstract thinking develops, } \\
\text { mainly in relation to others } \\
\text { Late adolesceling autonomy (away }\end{array}$ & $\begin{array}{l}\text { Target health promotion messages as for early } \\
\text { from parents) }\end{array}$ & $\begin{array}{l}\text { adolescence; specifically address issues of risk } \\
\text { to self as well as others. }\end{array}$ \\
& $\begin{array}{l}\text { Complex abstract thought and } \\
\text { further development of identity } \\
\text { and body image }\end{array}$ & $\begin{array}{l}\text { Social autonomy; splitting of } \\
\text { peer group into smaller groups } \\
\text { and couples }\end{array}$ & $\begin{array}{l}\text { Health promotion messages can address many } \\
\text { possible outcomes of an action; targeting of } \\
\text { messages at partners and close friends. }\end{array}$ \\
\hline
\end{tabular}


narrow casting, using sustained and planned approaches to communications, Rigorously Strategies should be on behalf of adolescents rather than directed at adolescents. ${ }^{29}$ The third strategy is peer intervention; peer intervention is a drug prevention strategy basing individual peer groups. It contains different methods including development of core strategy for disconnection with peer groups, using targeted and highly structured approaches, focusing on current and former drug users to reduce harms, drawing on current and former drug users, providing information, skills and support, and facilitating links to health, welfare and rehabilitation services. ${ }^{29}$ The forth strategy is parent support, this is family based drug abuse prevention strategy. It includes the use of telephone and face-to-face parent peer support, offering formal parent education workshops and seminars, providing both reactive and outreach services, focusing on critical transition from primary to secondary school, targeting socially disadvantaged, culturally, and linguistically diverse, and adolescent parents, and encouraging modeling appropriate behavior and developing a habit of communication. The fifth strategy is community strengthening, this community based drug abuse prevention strategy. It is based on building resilience and supporting neighborhoods and communities of interest, encouraging community groups, local businesses and public services to work together, disseminating research project information, resources and ideas, strengthening local capacity through training, facilitation and coordination, development of local drug strategies involving all relevant sectors and groups, helping to manage public spaces and support economic development, and development of youth-focused and early interventions response. $^{29}$

\section{RESILIENCE}

Youth are exposed to drug abuse through different factors including individual and environmental factors. Community, peers, family etc. could be either a risk to drug abuse or a protective factor among youths (Table 2). Recognizing that adolescents use drugs often or in part to promote health and well-being and often engage in more than one risky behavior and that these behaviors often have common underlying predisposing factors, evidence is growing that effective health promotion interventions for a specific risk or protective factor are both highly effective and also likely to have direct effects on drug prevention or reduction among the youth. ${ }^{29}$ Interventions on youth drug use and emotional wellbeing covering whole schools, for example, are highly effective in reducing other problems, such as school dropout, violence and teen. ${ }^{3}$ It means giving attention to the full picture- - the substances (regulate supply to ensure the quality of substances, and enact appropriate restriction), the environments (promote social and physical contexts that encourage moderation and are stimulating and safe) in which they are used and in which people live, and the individuals (increase health capacity and resilience and develop active responsible citizens) who use those substances and shape the environments. ${ }^{4}$ Alcohol and other drugs should be prevented at the following levels:

(i) Individual level-Peer interventions, including peer education; youth recreation programmes; and mentoring programmes;

(ii) Family level_-Parent training and family interventions;

(iii) School level—Single issue, curriculum based education and "whole school" organisation and behaviour management interventions;

(iv) Community level_Local environmental change (such as policing policy, safety issues)

(v) National level-Health service reorganisation, employment and training, law and policing changes, social marketing, and socioeconomic change. ${ }^{10}$

Interventions on physical and sexual abuse and emotional wellbeing covering whole schools can be more effective at reducing drug abuse and related harms. For example, studies showed that all adolescents who participate in bullying,

\begin{tabular}{|c|c|}
\hline & Environmental Factors \\
\hline Community & $\begin{array}{l}\text { The community of youth lives in influences his or her drug use behavior. Particularly youth who live in } \\
\text { disorganized communities-those with higher rates of drug abuse. When opportunities are available in a } \\
\text { community for positive participation, children are less likely to engage in substance use and other problem } \\
\text { behaviors. }\end{array}$ \\
\hline Family & $\begin{array}{l}\text { Family characteristics are very important in determining risk.e.g youth living with both biological parents are } \\
\text { less likely to use drugs, and they use, they are likely to use drugs less frequently. However, when parents have } \\
\text { conversation with their children about drugs earlier, their initiation of drug may be delayed. }\end{array}$ \\
\hline Peers & $\begin{array}{l}\text { Drug abuse behaviors is one of the many areas in which youth are influenced by their peers. Young people who } \\
\text { regularly attend religious services, socially competent, with a belief in what is "right" or "wrong" are less likely to } \\
\text { engage in problem behaviors. } \\
\text { Individual factors }\end{array}$ \\
\hline Biological factors & $\begin{array}{l}\text { Studies have found that age, physical development, and gender have a dramatic effect on youth'drug abuse } \\
\text { behavior. }\end{array}$ \\
\hline $\begin{array}{l}\text { Attitudes Favorable } \\
\text { Toward Antisocial } \\
\text { Behavior and Drug Use }\end{array}$ & $\begin{array}{l}\text { Youth who express positive attitudes toward drug use are at higher risk for subsequent drug use. However, } \\
\text { young people who condone antisocial behavior are more likely to not to engage in a variety of problem } \\
\text { behaviors, including drug use. }\end{array}$ \\
\hline
\end{tabular}


whether they are the perpetrator, the victim, or a combination of both roles, have been shown to have increased risk of mental health disorders and psychosocial problems when compared with those who do not participate. ${ }^{30}$

\section{ROLE OF INDIVIDUAL HEALTH WORKERS}

Services for the prevention and treatment of substance misuse and substance use disorders have traditionally been delivered separately from other mental health and general health care services. Despite of this, substance abuse problems and SUDS are perceived by many as personal, family, or social problems, best managed at the individual and family levels, sometimes through the existing social infrastructure (school, places of worship, etc.) and when necessary through civil and criminal justice interventions. ${ }^{31}$ In Rwanda, majority receive treatment delivered by programs that geographically, financially, culturally, and organizationally separate from mainstream healthcare. Despite compelling national need for treatment of patient with SUDs, majority of staff working in health care system may not be trained and such individual health professional is likely to accept patients with SUDs. ${ }^{32}$ Therefore, integrating addiction in health curriculum in country such as Rwanda is of paramount importance. Some of health professional may still perceive substance abuse and substance use disorders as a social or criminal problem, and not considered as a disease that deserved prevention services with a responsibility of health care systems. ${ }^{32,33}$

Today, costs associated with substance use disorders are not limited to health care but also expands to criminal justice system, child welfare system military and other security system, integrating services for primary care, mental health, financial system, school system, family system to mention few, and substance use-related problems together produces the best outcomes and provides the most effective approach for supporting whole-person health and wellness. ${ }^{16}$ There are many evidences supporting the need for this integration, (i) Substance use, mental disorders, and other general medical conditions are often interconnected; (ii) Integration has the potential to reduce health disparities; (iii) delivering substance use disorder services in mainstream health care can be cost-effective and may reduce intake/treatment wait times at substance use disorder treatment facilities; and (iv) Integration can lead to improved health outcomes through better care coordination. ${ }^{35}$ However, despite health-related problem associated with substance use disorders, SUDs have never been insured, treated, monitored, or managed like other chronic illnesses. ${ }^{32}$

Rwandan health care reform laws and a wide range of other trends in health care landscape need to development various evidence-based behavioral interventions, medications, clinical monitoring systems, and recovery support services that will make this type of chronic care management possible likely by the same healthcare teams that currently treat other chronic illnesses. ${ }^{32}$ Despite the low efficacy of most health promotion messages at individual level, health professionals do have a role in health promotion in their clinical interactions with young people abusing or suffer from substance use disorders. In addition, health promotion discussions about drugs during routine general practice visits can reduce drug use, although messages are more effective if target at patients with SUDs who are contemplating change and help patients to go through the following stages of change: precontemplation, contemplation, preparation, action, maintenance and relapse. ${ }^{10}$

Patients themselves report that health promotion advice from their doctor is best received if it takes account of their receptiveness, is conveyed in a respectful tone, avoids preaching, shows support and caring, and shows understanding of them as unique individuals. ${ }^{3}$ The aforementioned issues underline the importance of adequate measures to prevent youth with substance use disorders, and to strengthen health promotion activities in general. To reach this goal, it is important to address health professionals (e.g. physicians, psychologists, etc.) working in health system. With current problems related to youth with SUDs, National University (UR) need to integrate Postgraduate study courses and to provide the knowledge enabling health professionals to work with addicted individuals not only with substance use but also other addictions and to promote prevention initiatives.

\section{REFERENCES}

1. Ngamije $\mathrm{J}$ and Yadufashije $\mathrm{C}$. Drugs Use among the Youth In Rwanda: A public Health Concern and Family's Challenge. International Journal of emergencies computer and technology 2016; 3(9): 4591-4603.

2. Kanyoni M, Gishoma D and Ndahindwa V. Prevalence of Psychoactive substance use among youth in Rwanda. BMC Research Notes 2015; 8:10.

https://doi.org/10.1186/s13104-015-1148-2

3. Escadon R and Galvez C. Free from drugs and dddictions. Mandrid: Safeliz, 2005

4. Canadian Institute for Substance Use Research. Understanding Substance Use: A health promotion perspective 2017.

5. Ministry of health,2014

6. Rao U. Links between depression and substance abuse in adolescents: neurobiological mechanisms. Am J Prev Med 2006; (6 Suppl 1): S161-74.

https://doi.org/10.1016/j.amepre.2006.07.002

7. Rao $U$ and Chen LA. Neurobiological and psychosocial processes associated with depressive and substance-related disorders in adolescents. Curr Drug Abuse Rev,2008,1(1):68-80. https://doi.org/10.2174/1874473710801010068

8. Castellanos-Ryan N, O'Leary-Barrett and Conrod PJ. Substance-use in Childhood and Adolescence: A Brief Overview of Developmental Processes and their Clinical Implications, J Can Acad Child Adolesc Psychiatry 2013; 22(1): 41-46.

9. Kandel BD and Logan JA. Patterns of drug use from adolescence 
to young adulthood: I. Periods of risk for initiation, continued use, and discontinuation. Am J Public Health 1984; 74(7): 660-666. https://doi.org/10.2105/AJPH.74.7.660

10. Viner R and Macfarlane A. Health Promotion. BMJ 2005; 330(7490): 527-529.

https://doi.org/10.1136/bmj.330.7490.527

11. Tapert SF, Granholm E, Leedy NG and Brown SA. Substance use and withdrawal: neuropsychological functioning over 8 years in youth. $\mathrm{J}$ Int Neuropsychol Soc 2002; 8: 873-883. https://doi.org/10.1017/S1355617702870011

12. Best JR, Miller PH and Naglieri JA. Relations between executive function and academic achievement from ages 5 to 17 in a large, representative national sample. Learn. Individ Differ 2011; 21: 327-336.

https://doi.org/10.1016/j.lindif.2011.01.007

13. Jordan CJ and Andersenon SL. Sensitive periods of substance abuse: Early risk for the transition to dependence. Developmental Cognitive Neuroscience 2017; (25): 29-44 https://doi.org/10.1016/j.dcn.2016.10.004

14. Meda SA, Gueorguieva RV, Pittman B, Rosen RR, Aslanzadeh F, Tennen $\mathrm{H}$, et al. Longitudinal influence of alcohol and marijuana use on academic performance in college students. PLoS ONE 2017; 12: e0172213.

https://doi.org/10.1371/journal.pone.0172213

15. Sjoerds Z, Van Tol MJ, Van den Brink W, Van der Wee NJ, Van Buchem MA, Aleman A, et al. Family history of alcohol dependence and gray matter abnormalities in non-alcoholic adults. World J. Biol. Psychiatry 2013; 14: 565-573. https://doi.org/10.3109/15622975.2011.640942

16. Myrick H, Anton RF, Li X, Henderson S, Drobes D, Voronin K, et al. Differential brain activity in alcoholics and social drinkers to alcohol cues: relationship to craving. Neuropsychopharmacology 2004; 29: 393-402.

https://doi.org/10.1038/sj.npp.1300295

17. Dager AD, Anderson BM, Rosen R, Khadka S, Sawyer B, JiantonioKelly RE, et al. Functional magnetic resonance imaging (fMRI) response to alcohol pictures predicts subsequent transition to heavy drinking in college students. Addiction 2014; 109: 585-595.

https://doi.org/10.1111/add.12437

18. Crews FT, and Nixon K. Mechanisms of neurodegeneration and regeneration in alcoholism. Alcohol Alcohol 2009; 44: 115-127. https://doi.org/10.1093/alcalc/agn079

19. Squeglia LM, Tapert SF, Sullivan EV, Jacobus J, Meloy MJ, Rohlfing $\mathrm{T}$, et al. Brain development in heavy-drinking adolescents. Am J Psychiatry 2015; 172: 531-542.

https://doi.org/10.1176/appi.ajp.2015.14101249

20. Kirschmann EK, McCalley DM, Edwards CM and Torregrossa MM. Consequences of Adolescent Exposure to the Cannabinoid Receptor Agonist WIN55,212-2 on Working Memory in Female Rats. Front Behav Neurosci 2017; 11:137. https://doi.org/10.3389/fnbeh.2017.00137
21. Becker MP, Collins PF and Luciana M. Neurocognition in college-aged daily marijuana users. J Clin Exp Neuropsychol 2014; 36: 379-398.

https://doi.org/10.1080/13803395.2014.893996

22. Marconi A, Di Forti M, Lewis CM, Murray RM and Vassos E. Meta-analysis of the association between the level of cannabis use and risk of psychosis. Schizophr Bull 2016; 42: 1262-1269. https://doi.org/10.1093/schbul/sbw003

23. Reider $\mathrm{H}$ and Elbert $\mathrm{T}$. Rwanda - lasting imprints of a genocide: trauma, mental health and psychosocial conditions in survivors, former prisoners and their children, Confl Health 2013; $7: 6$. https://doi.org/10.1186/1752-1505-7-6

24. Niyonzima O. Rwanda Losing Over Rwf100Bn to Drug Abuse Annually. KT Press, Retrieved from https://ktpress.rw, 2018

25. MacLellan AT. Substance misuse and substance use disorders: why do they matter in Health care? Transactions of the American Clinical and Climatological associations 2017; 128:112-129.

26. World Health Organization. Global status report on alcohol and health. Geneva: WHO, 2011.

27. O'Donnell MP. Domains for health promotion. American Journal of Health Promotion. 1989, 3(3) 5.

https://doi.org/10.4278/0890-1171-3.4.71

28. Thomborou J, Patton G, Sawyer S, Olsson C, Webb-Pullman J, Catalano R and Godfrey C. Evidence-based health promotion: Resources for planning. No. 2 Adolescent health. Public Health Division, Department of Human Services, Melbourne, 2000. (http://www.dhs.vic.gov.au/phd/0003097).

29. Catford J. Illicit drugs: Effective prevention requires a health promotion approach. Health promotion Interventional 2011; 16(2)107-110.

https://doi.org/10.1093/heapro/16.2.107

30. Kaltiala-Heino R, Rimpela M, Rimpel M, Rantanen $P$ and Rimpela A. Bullying at school: an indicator of adolescents at " risk for mental disorders. Journal of Adolescence 2000; 23(6): 661-674. https://doi.org/10.1006/jado.2000.0351

31. White W. Slaying the Dragon: The history of Addiction Treatment and Recovery in America ( $2^{\text {nd }}$ Ed.). Bloomington, IL: Chestnut Health Systems,2014

32. MacLellan AT. Substance misuse and substance use disorders: why do they matter in Health care? Transactions of the American Clinical and Climatological associations 2017; 128:112-129.

33. Kessler RC, Aguilar-Gaxiola S, Berglund PA, CaraveoAnduaga JJ, De Wit DJ, Greenfield SF, et al. Patterns and predictors of treatment seeking after onset of a substance use disorder. Arch Gen Psychiatry 2001; 58: 1065-1071. https://doi.org/10.1001/archpsyc.58.11.1065

34. SAMHSA. Key Substance Use and Mental Health Indicators in the United States: Results from the 2015 National Survey on Drug Use and Health (No. HHS Publication No. SMA 16-4984), 2016.

35. Compton WM, Blanco $\mathrm{C}$ and Wargo EM. Integrating addiction services into general medicine. JAMA 2015; 314 (22):2401-02402. https://doi.org/10.1001/jama.2015.12741

\footnotetext{
Authors Contribution:

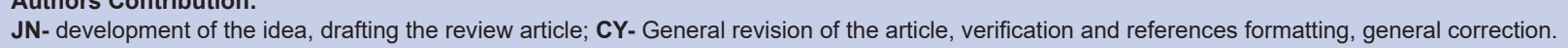

Work attributed to:

Department of Biomedical Laboratory Sciences, Faculty of Applied Fundamental Sciences, INES-Ruhengeri-Institute of Applied Sciences, and University of Tourism, Technology and Business studies.

Orcid ID:

Dr. Callixte Yadufashije - (ㄴ) http://orcid.org/0000-0002-3463-3725

Dr. James Ngamije - http://orcid.org/0000-0001-5302-5031

Source of support: There is fund received, Conflicts of Interest: None
} 